\title{
Psychotherapies with older people: an overview
}

\author{
Jason Hepple
}

\begin{abstract}
Psychotherapies with older people have been slow to develop, both theoretically and operationally, in the UK. This is due to ageism and the predominance of models of psychological development relevant to children and younger adults. Despite this, many have applied their practice and skills to psychological work in old age psychiatry, countering the dominance of the 'organic' model. An evidence and practice base exists to suggest that cognitive-behavioural therapy, interpersonal therapy, cognitive analytic therapy, psychodynamic and systemic approaches can help in a range of psychiatric problems in older people, including affective disorders, personality disorders and dementia. The inclusion of older people in existing psychotherapy services and the development of networks of practitioners whose support and supervision are encouraged are likely to be positive ways forward.
\end{abstract}

My aim here is to give readers an overview of the psychological therapies that have been applied to work with older people, in order to inform clinical work in old age psychiatry and to encourage interest, training and referral where resources and practitioners are available. Psychological therapies with older people have traditionally held a lowly position in old age psychiatry and in psychotherapy generally. This is due to a number of reasons, particularly ageism, which has been a great hindrance to development of expertise and services in this area. Negative stereotypes about the treatability of older people and a lack of psychotherapy theory that can speak to later life still have a pervasive negative effect on expectations and expertise. With the current high demand on old age psychiatry services for the assessment and treatment of early dementia, developments in services are focusing on biological models of illness and pharmacological treatments, again at the expense of psychological therapies.

Needless to say, this brief overview cannot investigate the topic in depth: for a more complete review see Hepple et al (2002a).

\section{Background}

Ageism, or the discrimination against people on the grounds of age alone, has been slow to gain public awareness in Western society. Although racism and sexism, for example, have been tackled in statute law in the UK, ageism is just surfacing in the collective consciousness of policy makers and clinicians. The National Service Framework for Older People (Department of Health, 2001) cites the elimination of ageism as a laudable aim, but does not go far in suggesting how this might realistically be achieved. It is interesting to consider the paradox that discrimination based on a universal experience (ageing and death) has been relatively slow to achieve public awareness compared with 'isms' that oppress minority groups in society. There may be many reasons for this: the prevalence of ageism among older people themselves (discouraging the formation of a 'minority group'); our need for robust denial-based defences to protect against frightening existential uncertainties (death, meaninglessness); and the notion of the demise of 'elderhood' in Western society in the 20th century. For a full discussion of these factors see Hepple (2004).

Even at the age of 49 himself, Freud considered older people (the over-50s by his reckoning) ineducable (Freud, 1905). This therapeutic nihilism has had a profound effect on the development of both psychotherapy theory and services for older people. Psychotherapy theory has tended to focus on childhood development and the developmental stages of infant, child and early-adult life, with later life being neglected as a developmental phase. An exception to this has been the work of Erikson (1966), who identified 'eight ages of man' in terms of dichotomies, with 'generality $v$. stagnation' and 'egointegrity $v$. despair' describing the developmental challenges of later life. The apparent linearity of this

Jason Hepple is a consultant psychiatrist and Medical Director of Somerset Partnership NHS and Social Care Trust (Magnolia House, 56 Preston Road, Yeovil, Somerset BA20 2BN, UK. E-mail: jason.hepple@sompar.nhs.uk). He is a clinical research fellow of the Peninsula Medical School and is a cognitive analytic therapy practitioner and supervisor. 
model, however, and the lack of elaboration of the nature of psychological development in later life over the 30 years since Erikson proposed it have left old age psychotherapy detached from the mainstream and without a firm theoretical base. In addition, the dominance of the biological or organic model in old age psychiatry and neuropsychology has tended towards 'brain-based' rather than 'psyche-based' explanations for all illness and distress in later life, where the imaging and charting of deficits takes priority over any meaningful dialogue about shared existential fears between professional and patient.

Murphy (2000) surveyed the prevalence and availability of psychological therapy services for older people in the UK. The respondents included a range of mental health and social care professionals, of whom $87 \%$ felt that their services failed to deliver to older people, with low expectations being reflected in the disproportionately low referral rates. For example, less than $1 \%$ of referrals involved patients over 75 years of age, although this group accounted for nearly $9 \%$ of the population. Interestingly, old age psychiatrists were less likely to refer the over$55 \mathrm{~s}$ for psychotherapy than were general adult psychiatrists. Despite all these problems, many psychotherapists, psychologists and psychiatrists have used various psychotherapies with older people with success and enthusiasm. Of particular note is the work of Martin (1944) and Hildebrand (e.g. Hildebrand, 1990), who can be seen as pioneers in this field. Many others, who will be mentioned in the sections below covering individual psychotherapies, have been determined to apply and develop different theoretical approaches in their work with older people and to share their experience and positivity. In contrast to the pessimistic starting point that psychotherapy with older people is 'too late' there is hope not only that it is not too late, but that for many it can be just in time.

\section{Cognitive-behavioural therapy}

Cognitive-behavioural therapy (CBT) is the form of psychotherapy most often used with older people. In controlled clinical studies it has been shown to be efficacious in the treatment of depression, anxiety and problematic behaviours in the context of dementia (for reviews of this literature see Teri et al (1994) and Wilkinson (2002)). In a series of studies with older people in the USA by GallagherThompson and colleagues (reviewed by Teri et al, 1994) CBT has been shown to be highly effective with depressed patients in both hospital and community settings as well as in individual and group formats. A more recent trial (Barrowclough et $a l, 2001)$ of the effectiveness of CBT $v$. supportive counselling on anxiety symptoms in older adults showed CBT to be both effective and superior to supportive counselling in terms of improvement in anxiety symptoms and self-rating of anxiety and depression over a 12-month period.

Cognitive-behavioural therapy focuses on negative thoughts and their reinforcing behaviours, attempting to identify dysfunctional cycles and to intervene with challenges to unhelpful thinking, the reduction of negative and avoidant behaviours and the introduction of positive behaviour patterns. Negative thoughts can be challenged by techniques that assess the evidence behind the thought, the 'thinking errors' that are present, the pragmatic effect of negative thoughts on overall well-being and the consideration of alternative viewpoints. The intensity with which thoughts are held can be rated and monitored through treatment, and the reinforcing avoidant behaviours can be tackled using a graded exposure model. In work with older people, writers in the field suggest some adaptations to CBT technique, including increased emphasis on maintaining the focus on the work, acknowledgement of feelings of guilt and helplessness following the onset of disability and other life events and an awareness of the interaction of somatisation and the physical symptoms of organic disease. Cognitive-behavioural therapy offers a structured, collaborative, brief and client-centred approach. The wide availability of this therapy for younger people in the UK makes it well positioned for further expansion into later-life work.

\section{Cognitive analytic therapy}

Cognitive analytic therapy (CAT) represents a modern integration of analytic (object relations theory) and cognitive psychotherapy traditions to provide a brief, structured and collaborative therapeutic journey from past trauma into reconnection with dialogue and meaning. In existence for less than 20 years, the evidence base, although in progress, is yet to be established, but there is interest in applying the model to older people and potential for the development of a therapy that truly speaks to later life through its emphasis on shared meaning in the context of the client's life story and the recognised importance of the 'dialogue', both cathartic and reparative, in the therapeutic relationship (Hepple, 2002). Traditional concepts from psychoanalytic theory and psychiatry (such as narcissism, borderline personality traits and post-traumatic syndromes) have recently been applied to later life from a CAT perspective (Hepple \& Sutton, 2004).

Later life can be a time when coping mechanisms are challenged by losses, disability and changes in 
social role. It is then that pre-existing trauma and low self-esteem can resurface to produce anxiety, depression and self-destructive behaviours, which need to be understood in terms of the person's whole life story. Cognitive analytic therapy can offer a coherent way of linking past and present, and may be well suited to work in later life because of its emphasis on the interpersonal and the need to find shared meaning and understanding in therapy across generational and cultural boundaries. Anthony Ryle, the originator of CAT, writes:

'Personality and relationships are not adequately described in terms of objects, conflicts or assumptions. They are sustained through an ongoing conversation within ourselves and with others - a conversation with roots in the past and pointing to the future. In their conversation with their patients, psychotherapists become important participants in this conversation and CAT, I believe, fosters the particular skills needed to find the words and other signs that patients need' (Ryle, 2000).

The following case vignette demonstrates the CAT approach in treating re-emergent trauma in late life.

\footnotetext{
Vignette

Mrs Y was a 67-year-old woman who had been admitted to an acute adult psychiatric unit following a serious suicide attempt related to her divorce from her second husband. She was treated for depression with medication and electroconvulsive therapy but was still an in-patient 2 years later, because attempts to discharge her had provoked immediate and serious self-harm. Although previously a highly competent and sociable person, she regressed into a child-like state of withdrawal and frozen watchfulness. One-to-one communication was difficult owing to her monosyllabic answers, repetition of 'I don't know' and tendency to terminate interviews. Anxiety management and graded exposure to improve social skills proved ineffective because of failure to engage Mrs Y meaningfully in the work. There were outbursts of anger (e.g. if there were small delays to ward routine) and staff reported feeling that Mrs Y 'knew everything that was going on' behind the penetrating stare.

It was known that Mrs $Y$ had been sexually abused by a relative for much of her adolescence, but it seemed impossible to engage her in dialogue about this. It remained unspoken (and unspeakable). Using some basic principles of CAT, although not attempting full therapy, Mrs Y's keyworker conducted daily 20minute one-to-one sessions with her in an attempt to reconnect her with her need to be heard and in contact with an other. The CAT concept of the zone of proximal development was used to establish where Mrs $Y$ was and how far, realistically, she might be able to go from there. She was in a cocoon and unable to venture out owing to owing to her unspoken fear. Previous therapeutic interventions had failed to match therapy aims with Mrs Y's potential at this
}

stage, leaving her outpaced and isolated. Her appearance and behaviour seemed a direct regression to the abused, terrified and watchful child who was paralysed into inactivity but who was trying to communicate her pain through her gaze alone. Focus on the here and now of the shortened sessions and preparedness to simply 'be with' Mrs Y allowed a gradual emergence from the cocoon and hesitant attempts at communicating the nature of the pain to a trusted other. Improvements in self-care and integration into ward life occurred, and work is still ongoing.

The case illustrates the need to establish a meaningful dialogue before any specific therapeutic models and techniques can be applied. It is hoped that Mrs Y will soon be able to start a formal CAT therapy in order to process the trauma of her earlier abuse.

\section{Psychodynamic therapy}

This broad range of therapies, stemming largely from the work of Freud, Klein and Jung, has been discussed widely in relation to later life (for reviews see Garner (2002) and Arden (2002)). Some empirical evidence exists to suggest that psychodynamic work with older people is at least as effective as CBT in dealing with depression (Thompson et al, 1987).

Psychodynamic approaches often centre on the development of insight into repressed unconscious material from earlier life experience and on the working through of this material in the therapeutic relationship. Experience has shown that the client's age can be an important factor in the nature of the transference and countertransference aspects of the therapy. Therapists may be reluctant to acknowledge the infantile needs of an elderly client because of a subconscious fear of the perceived dependence and helplessness that they might themselves experience in old age. Erotic transference may be ignored or ridiculed in the countertransference, and the client's situation may elicit in the therapist idealised care fantasies resulting from the therapist's unconscious fears and concerns about their own older family members. The psychodynamic model, however, is likely to be well suited to working with material derived from the client's 'feelings of abandonment and despair, intimacy and isolation, arrogance and disdain, stagnation and creativity as each of us struggles with the developmental task of "the third age" ' (Hildebrand, quoted in Hunter, 1989: p. 250).

\section{Interpersonal therapy}

Interpersonal therapy is a practical, focused, brief, manual-based therapy that can be applied by a range of professionals after a period of basic training. 
Its accessibility has generated considerable interest in its use with older people, and a reasonable evidence base exists to support its efficacy in the treatment of depression in older people, both in the acute phase and in relapse prevention (Reynolds et al, 1999).

Interpersonal therapy focuses on disturbances in current relationships, categorised into four domains: role transition, role dispute, abnormal grief and interpersonal deficit. A range of therapeutic interventions aim to improve communication, express affect and support renegotiated role relationships, with the effect of symptom reduction and improvement in functionality. Experience in applying interpersonal therapy to work with older people has suggested that it is directly applicable to the relationship and developmental issues relevant to people in later life. For a review of this area see Miller \& Reynolds (2002).

\section{Systemic (family) therapy}

Although the evidence base for the use of systemic approaches in work with older people is sparse, a model that looks at individuals in the context of their wider family and social system seems to have wide applicability (Pearce, 2002). A systemic approach may be particularly helpful in the context of communicating and processing the diagnosis of dementia in a family setting and also in unravelling the reinforcing factors in dysfunctional somatising and sick-role behaviour in older adults (Qualls, 2000). Systemic approaches can be used pragmatically both in one-off therapeutic assessments and in more formal therapy sessions following an established family therapy model.

The systemic approach recognises that presenting symptoms in the index patient may result from dysfunctional dynamics in the wider matrix of relationships surrounding the individual. By using techniques such as circular questioning (e.g. 'What do you think $X$ would say to that?'), positive connotation (e.g. 'You are such a close family that sometimes you care too much'), paradoxical intervention (e.g. 'So it seems that you have solved all your difficulties and don't need our help any longer'), reframing (e.g. 'It seems as if $X$ is flagging up the distress on behalf of the whole family') and exploration of the shared genogram (family tree), therapy may tip the system into positive change. The availability of professionals skilled in system approaches is likely to be highly beneficial as a consultative tool for those working directly with clients in old age psychiatry, who are well aware of the challenging family dynamics often uncovered by mental illness in late life.

\section{Psychotherapy in dementia}

For a detailed review of non-pharmacological treatments in dementia I recommend a recent $A P T$ article by Douglas et al (2004). They discuss the evidence supporting behavioural approaches in improving the behavioural and psychological symptoms of dementia (BPSD), reviewing some of the alternative therapy approaches and the evidence base for the more 'traditional' approaches on which I comment below. Rather than duplicate their review, I will comment from a more psychodynamic and CAT perspective.

Owing to the presence of often severe memory deficits in people with dementia, one-to-one psychotherapy is usually avoided. From an interpersonal and systemic point of view, however, the organic pathology itself is but one aspect of the individual's situation, and disability and distress can often be understood clearly in terms of psychological models rather than as neurological symptoms such as disinhibition or apathy. Laura Sutton has recently restated Tom Kitwood's 'malignant social psychology' of dementia care in the reciprocal-role terminology of CAT (Sutton, 2004). Maintaining a view of the person's pre-dementia personality structure and attending to the repetition of unhelpful role-play in the professional-client relationship is a promising way of processing the challenging dynamics of dementia care.

Over the years, various fairly superficial approaches have been used in dementia care, often using a group approach. Reminiscence therapy, reviewed by Thornton \& Brotchie (1987), is undergoing something of a resurgence in the UK. The idea of improving communication and self-esteem through reminiscence is undoubtedly helpful. However, there is a tendency for group reminiscence (remembering the sights and sounds of the Second World War, for example) to lump individuals into a 'cohort' more imagined by the younger carers than remembered by the older people themselves. At its worst, this behaviour verges on the ageist.

Reality orientation is widely used in dementia care and it works on the premise that people with dementia will benefit from environmental and interpersonal intervention that reorients them in terms of person, place and time and that corrects their misperceptions and forgotten reality. This approach has been manualised in an ambitiously titled publication The Way to Reality (American Hospital Association, 1976). Many working in dementia care, however, find that constant reality orientation can cause distress and the cyclical remembering and forgetting of losses and disabilities. Sutton (2004) calls this interaction 'outpacing to unbearably outpaced', remarking that it can recreate the most distressing 
aspects of cognitive impairment repeatedly in the care setting. An opposite approach, which gained many devotees in the 1970s, is Naimo Feil's validation therapy (Feil, 1982). The symbolic content of dialogue and interpersonal interaction is explored and, where possible, shared and validated by the carer, with no attempt to re-establish orientation in reality. This approach can be cathartic and reconnecting, although it requires a very active therapist to maintain engagement. In its broader applications, this approach has permeated many dementia care settings.

\section{What for whom?}

The choice of psychological approach will largely depend on availability of expertise, which is often sadly lacking because psychotherapies are still regarded as being unnecessary or ineffective for older people. In an ideal world, however, a range of therapies would be available, and given that some require considerably more time and resources than others, the following is a guide to deciding what might be best for whom.

\section{'Uncomplicated' depressive illness}

Cognitive-behavioural or interpersonal therapy may be offered in the first instance with or without pharmacological treatment. Both therapies may be useful in relapse prevention in those with recurrent depression. Interpersonal therapy may take preference where obvious tensions exist in current relationships, whereas $\mathrm{CBT}$ may suit a more cognitively minded patient. Cognitive-behavioural therapy should also be the first-line approach for pronounced anxiety symptoms and panic with avoidant behaviours.

\section{Depressive illness and borderline or narcissistic personality traits}

Patients with depressive illness complicated by antecedent borderline or narcissistic personality traits often have a history of traumatic experience in childhood or earlier in their adult lives and exist either in a highly dysfunctional systemic context or in relative isolation following severing of close interpersonal links. Cognitive analytic therapy or psychodynamic therapy is the treatment of choice.

\section{Depressive illness in dysfunctional family systems}

Depressive illness in late life is sometimes complicated by enmeshed and 'high expressed emotion' family or systemic relationships. Systemic (family) therapy is indicated if at least some of the system can be engaged in it.

\section{Somatisation disorders}

Cognitive-behavioural therapy is probably the firstline approach, but if the somatic or dissociative symptoms can be traced to earlier trauma a more exploratory therapy such as CAT or psychodynamic therapy may be needed.

\section{Psychological approaches to dementia care}

Insights from psychodynamic theory and CAT can contribute to an understanding of the role-play between the carer and the person with dementia and help prevent interaction that reinforces the isolation and alienation experienced. Behavioural approaches may be helpful for clusters of repetitive behavioural disturbances in more severe dementia. Family and systemic approaches can be useful in exploring a diagnosis of early dementia. A general approach based loosely on the principles of validation therapy, with time for reminiscence and life review, is likely to provide a humane theoretical backdrop to dementia care in many settings.

\section{Developing services}

A psychological perspective is a key part of the biological, psychological and social triad underpinning good psychiatric treatment. However, it is probably unreasonable to expect a large input of resources for specialist training and the appointment of dedicated therapists to work with older people. A gradually increasing awareness of, and skills in, psychotherapies among 'front-line' workers will probably deliver the most overall benefit.

Where services exist for adults of working age then age barriers to referral should be removed and old age service professionals should work in collaboration with colleagues in general adult psychiatry. One way of doing this is to set up 'psychological therapies networks' within trusts or institutions. Box 1 outlines the procedure for establishing such a network, which my colleagues and I have described in greater detail elsewhere (Hepple et al, 2002b).

The community psychiatric nurses, social workers, occupational therapists and in-patient and day patient staff engaged in psychotherapeutic work with patients and clients should be supervised by experienced therapists. A consultation model of supervision rather than a formal therapy model can be helpful to both patients and staff (Sutton, 2004). 
Box 1 How to establish a psychological therapies network for older people

- Form an executive committee to oversee the evolution of the network and to liaise with purchasers, funding organisations, users and carers, and the wider health services. The committee's members should be senior practitioners and managers working for the organisation as a whole.

- Remove all age criteria from operational policies relating to psychological treatments.

- Encourage professionals to link across the boundaries of age-specific services and to find a shared interest in a particular psychological therapy.

- Conduct a survey to identify who is currently practising which therapy, what training they have had and what practitioner supervision structures exist.

- Using the available evidence and local experience, identify the psychotherapies that the organisation wishes to provide and define how much (in terms of practitioner hours per week) of each should be available in each locality.

- Identify practitioners and practitioner supervisors in each therapy, paying heed to the requisites of the relevant national psychotherapy organisations (such as the British Confederation of Psychotherapists).

- Allocate protected time to each practitioner to engage in psychotherapy work.

- Appoint a coordinator for each locality to act as a troubleshooter and manager of the practitioner supervision structures.

- Arrange for the coordinator to meet each practitioner at regular intervals to discuss their role within the network and their training needs.

- Ensure that those working with older people have the same access to training and supervision as those working with younger clients.

- Develop protocols for allocating a particular client to a particular therapy.

- Collect or create information on the therapies being offered to enable clients to express informed preferences.

- Identify more-experienced practitioners to provide psychotherapy assessments in difficult cases and to act as consultants in the application of psychotherapeutic principles in day-to-day clinical work.

- Decide under what circumstances the person delivering a psychotherapy can also be the client's care coordinator, responsible medical officer or equivalent.

- Establish a regular programme of education, training and sharing of ideas and experience.

- Establish systems for auditing practice, outcomes and clients' views.

\section{Moving forward}

A range of psychological therapies have proved themselves effective in the management of older people with mental health problems, both in controlled trials and the growing body of clinical experience and case material in the literature. There is little prospect of funding for large-scale controlled studies involving older people, and if a therapy is shown to be effective in treating younger people, then there seems no reason why older people should be excluded from the benefits it may offer. The growing movement for old age psychiatry to become primarily a 'brain specialty' can only be countered by individual clinicians taking the initiative to gain experience and supervision in psychological therapies as a core part of their professional work. It is now mandatatory for psychiatric trainees to gain experience in a range of psychological therapies. Specific training in psychological work with older people for specialist registrars in old age psychiatry would be a positive move towards equipping old age psychiatrists with the full complement of skills they need to help their patients. Psychiatrists will always play a key role in assessment and in encouraging other staff's understanding of each patient in their biological, psychological and social context. To honour this role, we must ensure that the psychological dimension does not continue to take a back seat to biological and social-care models.

\section{References}

American Hospital Association (1976) The Way to Reality: Guide for Developing a Reality Orientation Program. Chicago, IL: American Hospital Association.

Arden, M. (2002) Psychodynamic therapy. In Psychological Therapies with Older People. Developing Treatments for Effective Practice (eds J. N. Hepple, J. Pearce \& P. W. Wilkinson). Hove: Brunner-Routledge.

Barrowclough, C., King, P., Colville, J., et al (2001) A randomised trial of effectiveness of cognitive-behavioural therapy and supportive counselling for anxiety symptoms in older adults. Journal of Consulting and Clinical Psychology, 69, 756-762.

Department of Health (2001) A National Service Framework for Older People. London: Department of Health.

Douglas, S., James, I. \& Ballard, C. (2004) Non-pharmacological interventions in dementia. Advances in Psychiatric Treatment, 10, 171-177. 
Erikson, E. (1966) Eight ages of man. International Journal of Psychoanalysis, 2, 281-300.

Feil, N. (1982) Validation. The Feil Method. Cleveland, OH: Edward Feil Productions.

Freud, S. (1905) On psychotherapy. Reprinted (1953-1974) in the Standard Edition of the Complete Works of Sigmund Freud (trans. \& ed. J. Strachey), vol. 7. London: Hogarth Press.

Garner, J. (2002) Psychodynamic work and older adults Advances in Psychiatric Treatment, 8, 128-135.

Hepple, J. (2002) Cognitive analytic therapy. In Psychological Therapies with Older People. Developing Treatments for Effective Practice (eds J. N. Hepple, J. Pearce \& P. W. Wilkinson). Hove: Brunner-Routledge.

Hepple, J. (2004) Ageism in psychotherapy and beyond. In Cognitive Analytic Therapy in Later Life. A New Perspective on Old Age (eds J. Hepple \& L. Sutton). Hove: BrunnerRoutledge.

Hepple, J. \& Sutton, L. (eds) (2004) Cognitive Analytic Therapy in Later Life. A New Perspective on Old Age. Hove: Brunner-Routledge.

Hepple, J., Pearce, J. \& Wilkinson, P. (eds) (2002a) Psychological Therapies with Older People. Developing Treatments for Effective Practice. Hove: Brunner-Routledge.

Hepple, J., Wilkinson, P. \& Pearce, J. (2002b) Psychological therapies with older people: an overview. In Psychological Therapies with Older People. Developing Treatments for Effective Practice (eds J. N. Hepple, J. Pearce \& P. W. Wilkinson). Hove: Brunner-Routledge.

Hildebrand, H. P. (1990) Towards a psychodynamic understanding of later life. In Clinical and Scientific Psychogeriatrics (eds M. Bergener \& S. I. Finkel). New York: Springer.

Hunter, A. J. G. (1989) Reflections on psychotherapy with ageing people, individually and in groups. British Journal of Psychiatry, 154, 250-252.

Martin, L. J. (1944) A Handbook for Old Age Counsellors. San Francisco, CA: Geertz.

Miller, M. D. \& Reynolds, C. F. (2002) Interpersonal psychotherapy. In Psychological Therapies with Older People. Developing Treatments for Effective Practice (eds J. N. Hepple, J. Pearce \& P. W. Wilkinson). Hove: Brunner-Routledge.

Murphy, S. (2000) Provision of psychotherapy services for older people. Psychiatric Bulletin, 24, 181-184.

Pearce, J. (2002) Systemic therapy. In Psychological Therapies with Older People. Developing Treatments for Effective Practice (eds J. N. Hepple, J. Pearce \& P. W. Wilkinson). Hove: Brunner-Routledge.

Qualls, S. H. (2000) Therapy with ageing families: rationale, opportunities and challenges. Ageing and Mental Health, 4, 191-199.

Reynolds, C. F., Frank, E. \& Perel, J. M. (1999) Nortriptyline and interpersonal psychotherapy on maintenance therapies for recurrent major depression: a randomised controlled trial in patients older than 59 years. JAMA, 281, 39-44.

Ryle, A. (2000) Origins of CAT. http://www.acat.me.uk/ catorigins.php

Sutton, L. (2004) Cultures of care in severe depression and dementia. In Psychological Therapies with Older People. Developing Treatments for Effective Practice (eds J. N. Hepple, J. Pearce \& P. W. Wilkinson). Hove: Brunner-Routledge.

Teri, L., Curtis, J., Gallagher-Thompson, D., et al (1994) Cognitive/behaviour therapy with depressed older adults. In Diagnosis and Treatment of Depression in the Elderly: Proceedings of the NIH Consensus Development Conference (eds L. S. Schneider, C. F. Reynolds, B. Lebowitz, et al). Washington, DC: American Psychiatric Press.

Thompson, L., Gallagher, D. \& Breckenridge, J. S. (1987) Comparative effectiveness of psychotherapies for depressed elders. Journal of Consultant and Clinical Psychology, 55, 385-390.

Thornton, S. \& Brotchie, J. (1987) Reminiscence: a critical review of the literature. British Journal of Clinical Psychology, 26, 93-111.

Wilkinson, P. (2002) Cognitive behaviour therapy. In Psychological Therapies with Older People. Developing Treatments for Effective Practice (eds J. N. Hepple, J. Pearce \& P. W. Wilkinson). Hove: Brunner-Routledge.

\section{MCQs}

1 Ageism:

a is a psychological defence

b creates negative stereotypes of older people

c is mainly found among the young

$\mathrm{d}$ is an inevitable response to ageing

e is an NSF target.

2 Psychological therapy services for older people:

a are widespread

b attract low referral rates

c are disconnected from general psychotherapy services

$\mathrm{d}$ are a low priority in the NHS

e can sometimes be offered 'just in time'.

3 CBT with older people:

a is an effective treatment for depression

$\mathrm{b}$ is an effective treatment for anxiety disorders

c is an effective treatment for bipolar disorder

d challenges negative thoughts

e challenges avoidant behaviours.

4 The following are focuses for interpersonal therapy with older people:

a role transition

b normal grief

c interpersonal deficit

d reciprocal roles

e the 'wise old man'.

5 The following have been used in dementia care:

a cognitive analytic therapy

b personal construct therapy

c behavioural therapy

d social role valorisation

e validation therapy. 